\title{
The Application of Calphad Calculations to Ni-BaSed Superalloys
}

\author{
N. Saunders\$, M. Fahrmann^ and C. J. SmallA \\ \$Thermotech Ltd., Surrey Technology Centre, The Surrey Research Park, Guildford, Surrey GU2 5YG, U. K. \\ ^Special Metals Corporation, 3200 Riverside Drive, Huntington, WV 25705-1771, U. S. A. \\ ARolls-Royce plc., PO Box 31, Derby DE24 8BJ, U. K.
}

\begin{abstract}
In recent years thermodynamic modelling via the CALPHAD method has been extensively applied to industrial alloys of many types. Although pertaining to equilibrium conditions, use has shown that valuable information can be gained for a variety of practical applications. A paper presented at the last Seven Springs meeting gave some theoretical background to the CALPHAD method and described the development of the methodology to Ni-based superalloys. The main purpose of that paper was to provide validation of results against an extensive experimental literature which, at the time, concentrated on $\gamma / \gamma^{\prime}$ equilibria and liquid/solid equilibria. The present paper will present an extension of the validation process to take into account $\eta$ formation and provide a review and examples of the practical application of the CALPHAD method to industrial alloys. It will expand on some of the topics briefly raised in the previous paper and demonstrate that the CALPHAD route is readily extendable to conditions that depart from equilibrium. It will also be shown that it can be used to provide fundamental input for calculations of physical and mechanical properties.
\end{abstract}

\section{Introduction}

In a previous paper the construction of a themodynamic database for calculation of multi-component phase equilibria in Ni-based superalloys was decscribed ${ }^{1}$. In conjunction with an appropriate software package, such as Thermo-Calc ${ }^{2}$ (used in the present studies), phase equilibria for multi-component Ni-based superalloys can be readily calculated. Numerous comparisons between calculation and experiment were given for $\gamma / \gamma^{\prime}$ phase equilibria and liquid/solid equilibria, and general phase equilibria calculations for some commercial alloys were shown. The paper concentrated on $\gamma / \gamma^{\prime}$ alloys touched on aspects to do with the extension of the CALPHAD method to non-equilibrium transformation and also the prediction of fundamental properties such as anti-phase domain boundary (APB) and stacking fault (SFE) energies. Since this previous paper, the database has undergone substantial development, with the inclusion of new models, and its capabilities extended to new types of alloys, in particular to general NiFe-based superalloys and Re-containing single crystal alloys. As part of this process, validation work has been undertaken by companies such as Special Metals Corporation. and Rolls-Royce plc.

It has now also been used extensively world-wide and examples of its use are becoming well documented ${ }^{3,4,5,6,7,8}$. The purpose of the present paper is to first describe the extension of capability to NiFe-based superalloys, with emphasis on the formation of $\eta$ and $\gamma^{\prime \prime}$. A review of examples of its application will then be made, a number of which emphasise that the CALPHAD methodology can be extended to areas outside of the field of equilibrium studies. Finally, the recent extension of the database to include $\mathrm{Re}$ will be discussed

NiFe-based Superalloys

NiFe-based superalloys, such as alloy 706 and alloy 718, can exhibit substantially more complex phase behaviour than $\gamma / \gamma^{\prime}$ typc superalloys. They can be characterised by the formation of $\delta-\mathrm{Ni}_{3} \mathrm{Nb}, \gamma^{\prime \prime}$, Laves, $\eta$ as well as the usual types of TCP phases such as $\mu$ and $\sigma$. Transformation behaviour is more complex with the metastable $\gamma^{\prime \prime}$ being one of the primary hardening phases and a series of metastable states can arise during heat treatment.

Whilc the CALPHAD route straightforwardly provides an equilibrium calculation, it can also be used to calculate various metastable states that arise if certain phases do not form for 
kinetic reasons. This approach has been classically used in steels where cementite is formed in preference to graphitc during solid state transformations. In this case, graphite is "suspended" from the calculation by simply not considering it in the thermodynamic calculation; equilibrium is then calculated with cementite instead. Such metastable calculations have been made for numerous other material types, often with excellent success ${ }^{3}$. In a similar fashion such metastable calculations can be made for $\mathrm{NiFe}$-based superalloys, particularly (i) with respect to the formation of $\gamma^{\prime \prime}$ and (ii) alloys where $\gamma^{\prime}$ and $\eta$ compete. It is also possible to take into account kinetic effects using a combined thermodynamic and kinetic approach and work has been done on solidification modelling for NiFe-based superalloys.

\section{$\gamma^{\prime \prime}$ Formation}

$\gamma^{\prime \prime}$ is a metastable phase and in equilibrium conditions would not form. Figure 1 shows a calculated phase \% vs. Temperature plot for alloy 718. In the solid state the stable phases are $\gamma, \delta-\mathrm{Ni}_{3} \mathrm{Nb}$, $\gamma^{\prime}$, sigma, $\mathrm{MC}$ (which at low temperatures transforms to $\mathrm{M}_{23} \mathrm{C}_{6}$ ) and at close to $600^{\circ} \mathrm{C}, \alpha_{-} \mathrm{Cr}$ becomes stable (denoted $\mathrm{BCC}$ in the figure). However, after solution annealing and subsequent heat treatment at temperatures well below the $\delta$ solvus, the $\gamma^{\prime \prime}$ transformation is favoured over formation of stable $\delta$ because of its comparatively rapid transformation rate. In this circumstance, a metastable equilibrium is formed with $\gamma^{\prime \prime}$ instead of the equilibrium $\delta$, and Figure 2 shows a phase \% vs. Temperature plot for this case.

$\gamma^{\prime \prime}$ will transform to $\delta$ if left at temperature for sufficiently long times, as is well known from experiment, and Figure 3 shows the experimentally established TTT diagram for alloy $718^{\circ}$. Although the equilibrium calculation does not predict transformation rates, certain critical features are well matched. For example the stable $\delta$ solvus and the solvus temperatures for $\gamma$ and $\gamma^{\prime \prime}$ in the absence of $\delta$ are well matched, and very close to each other as would be expected in this alloy which is $\gamma^{\prime} / \gamma^{\prime \prime}$ hardened.

The TTT diagram also shows the formation of $\sigma$ and $\alpha-\mathrm{Cr}$ at low temperatures after long anneals. The case of $\alpha-\mathrm{Cr}$ formation is interesting as its solvus temperature is actually very close to that of $\sigma$. If its transformation rate is accelerated, for example by the application of stress or strain due to prior cold work, or if, in general, its transformation rate is faster than $\sigma$, there is the clear potential for it to form in accord with experimental studies ${ }^{10}$. In other $\gamma^{\prime \prime}$ hardened alloys such as 625 similar calculations can be made for the equilibrium and metastable state and good agreement with experiment is found.

\section{$\eta$ Formation.}

In $\mathrm{NiFe}$-based superalloys there is a tendency to design alloys with lower Al concentrations than in $\gamma / \gamma^{\prime}$ hardened alloys. This promotes the formation of $\delta$ if $\mathrm{Nb}$ is present but, if $\mathrm{Ti}$ is also present, the $\mathrm{Al} / \mathrm{Ti}$ ratio can become sufficiently low such that $\eta$ forms in preference to $\gamma^{\prime}$ as the equilibrium phase. This phenomenon is well known in certain $\gamma / \gamma^{\prime}$ alloys, such as some Nimonic types, but in an analogous fashion to the $\gamma^{\prime \prime} / \delta$ case the faster kinetics of $\gamma^{\prime}$ growth permits it to form in preference to $\eta$. The $\gamma^{\prime}$ will eventually transform to $\eta$ if left at temperature for sufficiently long periods, but if used at low temperatures the

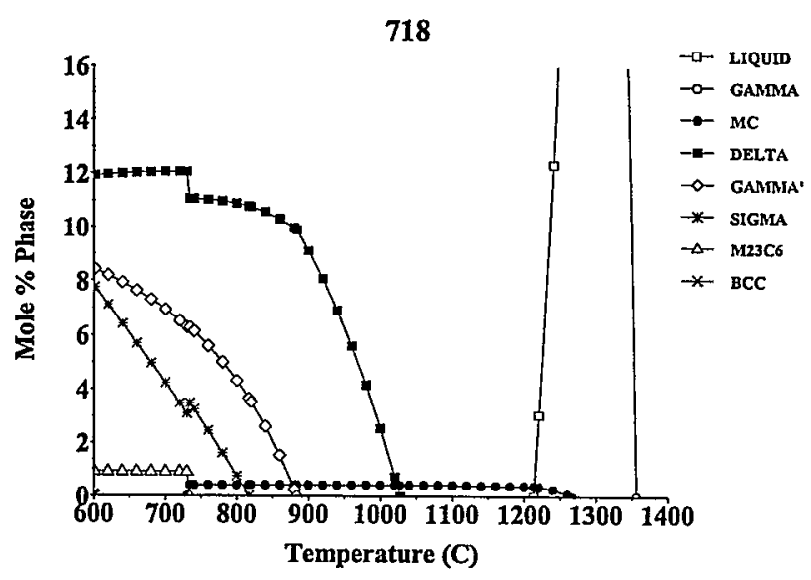

Figure 1 Calculated phase \% vs. Temp plot for alloy 718

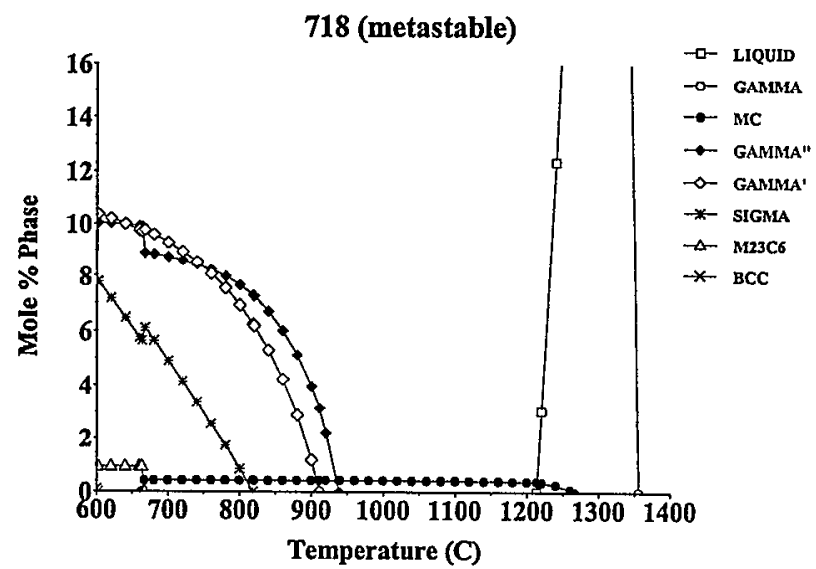

Figure 2: Calculated phase \% vs. Temp. plot for alloy 718 with delta phase suppressed

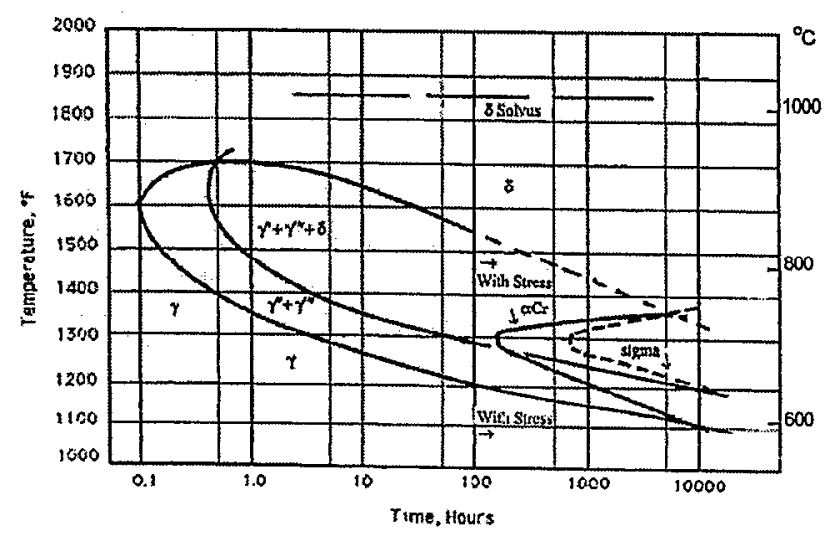

Figure 3: TTT diagram for alloy 718 from Basile Radavich ${ }^{9}$

$\gamma^{\prime} \rightarrow \eta$ transformation is suppressed and "normal" $\gamma^{\prime}$ strengthening can be achieved.

For such alloys it is valuable to have some knowledge of both the $\eta$ and $\gamma^{\prime}$ solvus temperatures. As part of a validation process at Special Metals a wide-ranging comparison was made with known behaviour of alloys and Table 1 shows results of the comparison. 
Whenever the presence of $\eta$ is noted, it was confirmed by phase extraction techniques combined with $\mathrm{x}$-ray diffraction analyses. The absence of $\eta$ was usually established in laboratory-type annealing studies of up to several thousand hours of exposure.

Table 1: Comparison between observed \& calculated $\eta$ formation ${ }^{\ddagger}$

\begin{tabular}{ccccc}
\hline Ni-base alloys & Obs. & Calc. & $\begin{array}{c}\eta \text { Solvus } \\
\text { Obs. }\left({ }^{\circ} \mathrm{C}\right)\end{array}$ & $\begin{array}{c}\eta \text { Solvus } \\
\text { Calc. }\left({ }^{\circ} \mathrm{C}\right)\end{array}$ \\
\hline NIMONIC alloy $80 A$ & No & No & - & - \\
INCONEL Alloy $X-750$ & Yes & Yes & 900 & 910 \\
NiCo-base alloys & & & & \\
\hline Exp. alloy Hll8964 & Yes $\left(850^{\circ} \mathrm{C}\right)$ & Yes & - & - \\
NIMONIC alloy 90 & No & No & - & - \\
NIMONIC alloy 105 & No & No & - & - \\
NIMONIC alloy 263 & Yes $\left(900^{\circ} \mathrm{C}\right)$ & Yes & - & - \\
NIMONIC alloy 115 & No & No & - & - \\
NIMONIC alloy PK33 & No & No & - & - \\
NIMONIC alloy EPK57 & Yes $\left(950^{\circ} \mathrm{C}\right)$ & Yes & - & - \\
NiFe-base alloys & & & & \\
\hline INCOLOY alloy 908 & Yes $\left(850^{\circ} \mathrm{C}\right)$ & Yes & - & - \\
NI-SPAN-C alloy 902 & Yes & Yes & 870 & 900 \\
INCONEL alloy 706 & Yes & Yes & 950 & 980 \\
NIMONIC alloy 901 & Yes & Yes & 980 & 1000 \\
NIMONIC alloy PE11 & Yes & Yes & $>900$ & 800 \\
NIMONIC alloy PE16 & No & No & - & - \\
\hline
\end{tabular}

It is clear that the database is providing high quality information on $\gamma^{\prime} / \eta$ phase competition and in a later section this capability was utilised to help design a new alloy for superheater tubes in advanced power plants.

\section{Solidification Modelling.}

A great deal of interest surrounds the solidification behaviour of NiFe-based superalloys. Unlike many $\gamma / \gamma^{\prime}$ types, a Laves phase can form during the final part of solidification. This phase is often metastable and can be removed by high temperature solution treatment, but in some cases it remains stable in the solid state. The CALPHAD method can be used to model aspects of solidification $^{11,12}$ that are otherwise quite difficult or time consuming to measure, e.g., segregation patterns and heat evolution. It is also possible to directly relate measured thermal effects to particular transformations.

Boutwell et al..$^{8}$ used an early version of the Ni-database to model the solidification behaviour of a 706 alloy. Figure 4 shows a Fraction Solid vs. Temperature plot calculated using the so-called "Scheil-Gulliver" model. This model assumes little or no back diffusion occurs in the solid phase during solidification and has been used with excellent success for a wide range of alloy types ${ }^{8}$.

Five critical points are calculated. The onset of solidification with the formation of $\gamma$ is marked A, B marks the formation of

$\ddagger$ INCONEL, INCOLOY, NIMONIC and Ni-SPAN-C are trademarks of the Special Metals Corporation family of companies.
MC carbide, $C$ the Laves phase start, $D$ the $\eta$ phase start and finally solidification is complete at point $\mathrm{E}$ where the fraction solid equals one. Experimental DTA confirmed that the calculated transformation temperatures were in good agreement with experiment (Table 2).

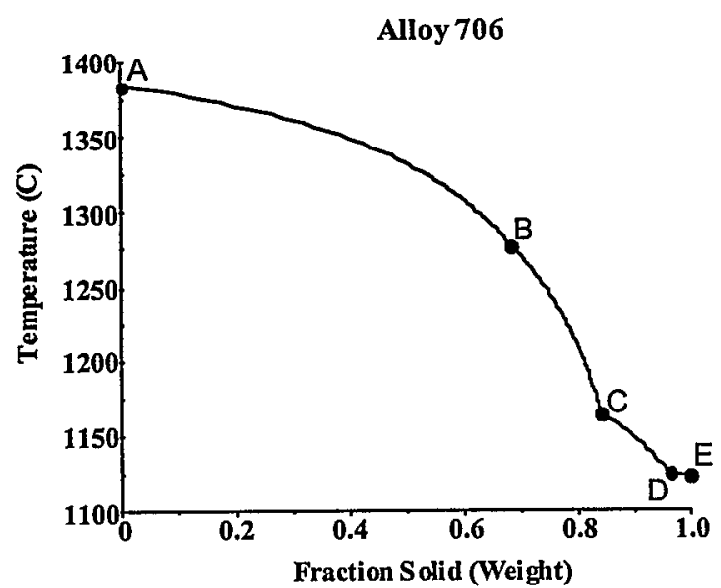

Figure 4: Fraction solid vs. Temperature plot for "Scheil-Gulliver" solidification of a 706 alloy

Table 2: Comparison between experimentally determined DTA results and a Scheil-Gulliver simulation for a 706 alloy $^{8}$

\begin{tabular}{cccccc}
\hline & Liquidus & $\begin{array}{c}\text { MC } \\
\text { start }\end{array}$ & $\begin{array}{c}\text { Laves } \\
\text { start }\end{array}$ & $\begin{array}{c}\eta \\
\text { start }\end{array}$ & $\begin{array}{c}\text { Solidific- } \\
\text { ation end }\end{array}$ \\
\hline Centre (DTA) & 1381 & 1240 & 1164 & & \\
Edge (DTA) & 1388 & 1261 & & & \\
Calculated & 1385 & 1277 & 1168 & 1126 & 1125 \\
\hline
\end{tabular}

The segregation patterns were calculated and Figure 5 shows the composition of $\gamma$ as a function of solid transformed. As well as providing results pertaining to the physical metallurgy of the casting, it is also possible to obtain thermo-physical data that can be used for casting simulations. Figure 6 : shows such a plot for the alloy investigated by Boutwell et al. ${ }^{8}$.

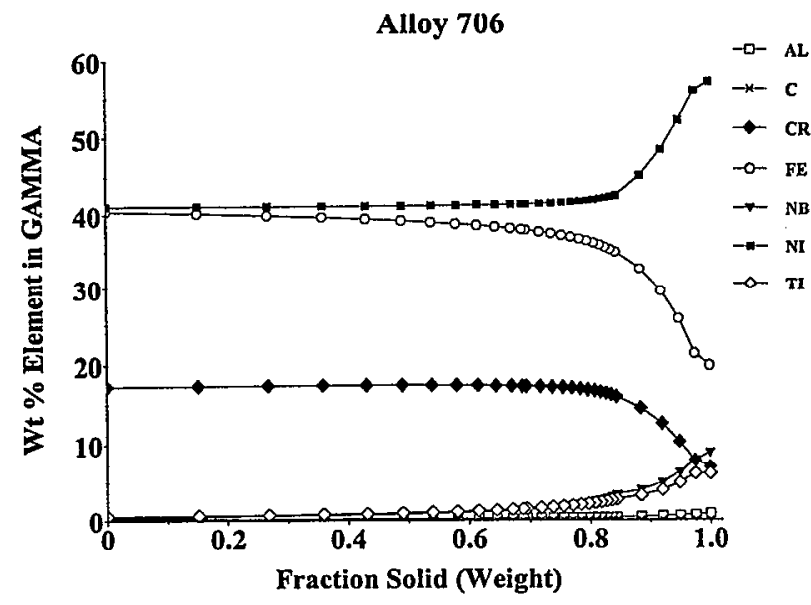

Figure 5: calculated segregation patterns in the $\gamma$ phase after solidification of a 706 alloy 


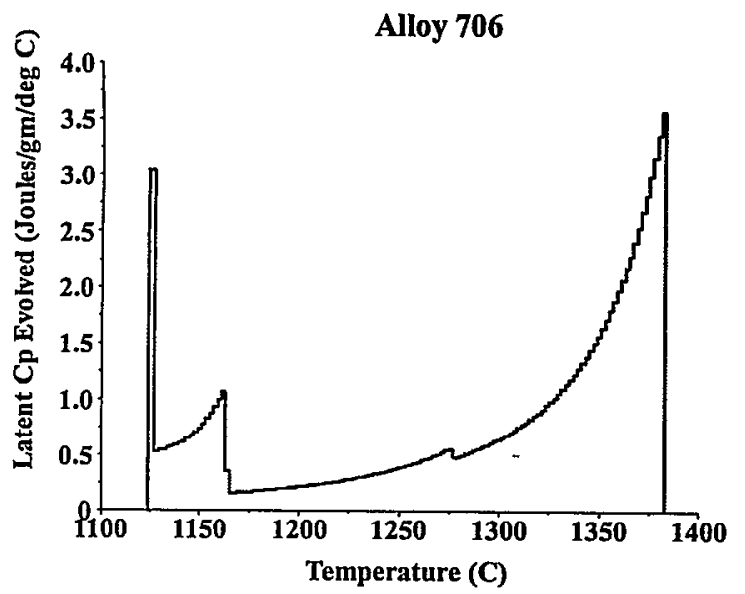

Figure 6: Plot of latent $C p$ of solidification vs. Temperature for a 706 alloy during "Scheil-Gulliver" solidification.

\section{Alloy Design and Development.}

Design of an Affordable New Alloy for Superheater Tubing in Advanced Power Plants.

The material requirements for new, advanced power plants means that older, more established alloys, such as Fe-based austenitic and ferritic steels will not match long term service requirements. To this end a design programme was instigated to produce a now Ni-based alloy that could be used for critical components and the following design targets were set ${ }^{6}$.

1. A metal loss of $<2 \mathrm{~mm}$ in 200,000 hrs. of operation in a hot flue gas/coal ash environment.

2. A minimum $100 \mathrm{MPa}$ rupture stress for $100,000 \mathrm{hrs}$ at $750^{\circ} \mathrm{C}$.

3. Metallurgical stability at $750^{\circ} \mathrm{C}$ for the same period of time.

4. Manufacturability in various sizes and lengths.

5. Ease of field installation, meeting weldability and bending requirements.

A baseline composition for the new allow was derived from the well established NIMONIC alloy 263 and further specifications added to it.

1. The $\mathrm{Cr}$ content was raised from 20 to $24 \mathrm{wt} \%$ to increase coal ash corrosion resistance.

2. The Mo level was drastically dropped from $5.8 \mathrm{wt} \%$ to $<1$ wt $\%$. This was partly done to counteract the increased $\mathrm{Cr}$ stabilising $\sigma$ and $\mu$. But corrosion testing in a simulated boiler environment also suggested that Mo could significantly reduce corrosion resistance.

3. Nb was added to improve weldability.

4. The alloy be $\gamma^{\prime}$-hardened with levels of up to $15-20$ vol. $\% \gamma^{\prime}$.

Using a "traditional" approach to alloy development would have normally mean that a series of alloys would have to be melted, tested and examined so that the effect of all of these changes could be understood. However, the use of the CALPHAD route meant that the change in phase "make-up" of the alloy could be easily calculated.

The development programme proceeded in a series of steps. The first step was to look at the effect of adding $\mathrm{Al}$ and $\mathrm{Ti}$ to the base alloy. The main aim of this exercise was to see how the competition between $\delta, \eta$ and $\gamma^{\prime}$ was affected by various levels of $\mathrm{Al}$ and $\mathrm{Ti}$ and, also, their ratio. So that the phase fields involving $\delta, \eta$ and $\gamma^{\prime}$ could be evaluated, an isothermal section of the base alloy at $750^{\circ} \mathrm{C}$ with $\mathrm{Al}$ and $\mathrm{Ti}$ as the axes was calculated. In this case $1 \mathrm{wt} \% \mathrm{Nb}$ was added to improve weldability of the final alloy.

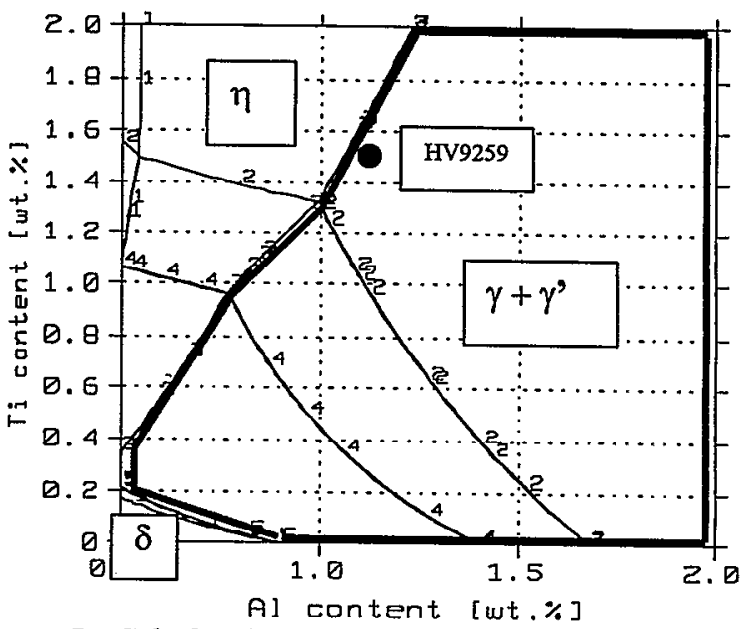

Figure 7: Calculated isothermal section at $750^{\circ} \mathrm{C}$ of $a$ baseline alloy $1 w t \% N b$ with $A l$ and $T i$ as axes. $\mu$ and $\delta$ labels show areas where these phases are predicted to form. The desired $y^{+} \gamma^{\prime}$ area is outlined within the bold line. For the sake of clarity carbide formation is not shown (HV9259 depicts the composition of an experimental heat)

It was clear that the alloy could be $\gamma^{\prime}$-hardened across a wide range of $\mathrm{Al}$ and $\mathrm{Ti}$ levels and the next step was to define the $\mathrm{Al}$ and $\mathrm{Ti}$ levels such that $15-20$ vol.\% $\gamma^{\prime}$ was produced. This was done by traversing the section shown in Figure 8 and constraining the amount of $\eta$ to be zero and varying the amount of Al.

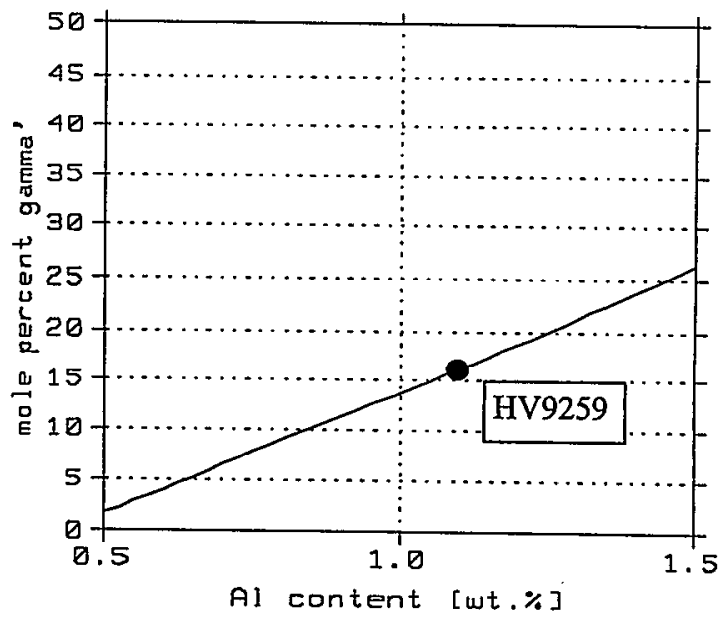

Figure 8: : Amount of $\gamma^{\prime}$ as a function of Al content added to the baseline alloy with $\mathrm{Nb}=1$ wt $\%$ calculated at $750^{\circ} \mathrm{C}$. The Ti-content follows the $\gamma^{\prime} / \gamma^{\prime}+\eta$ phase boundary in Figure 7.

This provided the maximum permissible $\mathrm{Ti}: \mathrm{Al}$ ratio to strengthen $\gamma$ without compromising phase stability. The flexibility of the Thermo-Calc software allowed this to be done and at the same 
time a plot of mole $\% \gamma^{\prime}$ could be plotted against the Al level in the alloy. When this level was between 15 and $20 \%$ the range of $\mathrm{Al}$ and $\mathrm{Ti}$ content was defined.

After these steps were complete, the effect of $\mathrm{Cr}$ and Mo was more closely examined. Figure 9 shows an isothermal section of the alloy at a constant $1.1 \mathrm{wt} \% \mathrm{Al}, 1.5 \mathrm{wt} \% \mathrm{Ti}$ and $1.0 \mathrm{wt} \% \mathrm{Nb}$ level with $\mathrm{Cr}$ and $\mathrm{Mo}$ levels varied. The section clearly shows that, as $\mathrm{Cr}$ levels rise above $23 w t \%, \sigma$ stability would be greatly enhanced and the level of Mo was kept well below the critical level of $3 w t \%$ for an alloy with $24 w t \% C r$.

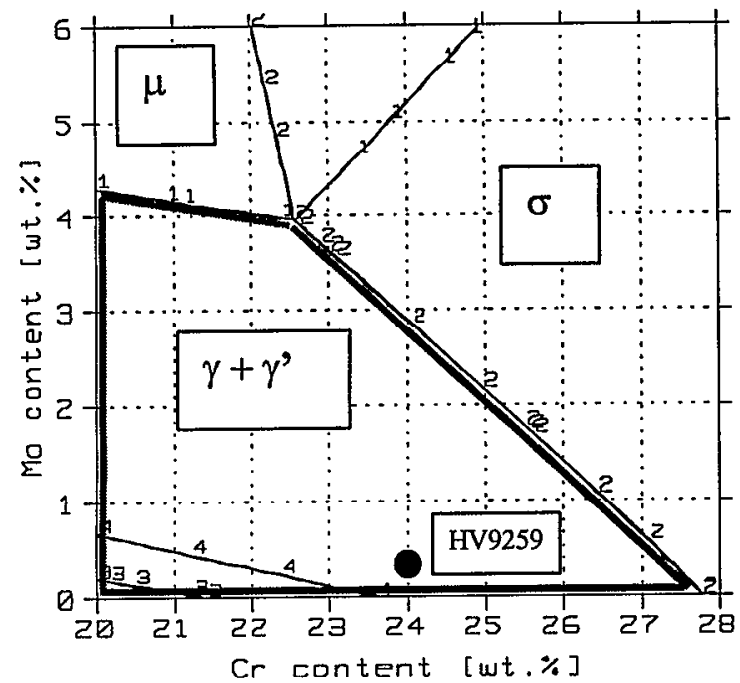

Figure 9: Calculated isothermal section at $750^{\circ} \mathrm{C}$ of a baseline alloy $+1.1 \% \mathrm{Al}+1.5 \% \mathrm{Ti}+1 \% \mathrm{Nb}$ (wt\%) with $\mathrm{Cr}$ and Mo as axes. $\mu$ and $\sigma$ labels shows areas were these phases appear and the desired $\gamma^{+} \gamma^{\prime}$ area is outlined within the bold line.

To confirm that alloys lying outside the calculated ranges of stability did indeed form deleterious phases, critical experiments were made. These supported the calculated phase diagrams. The ease of using the calculation route clearly enhanced the alloy design programme, which was both aided and expedited by having calculated information on phase amounts, at hand. This alleviated the necessity for a wide-ranging testing programme, significantly cutting costs and shortening development cycle times.

\section{Design of a New Gas Turbine Disc Alloy.}

In a recent paper, two of the present authors described the background to an alloy development programme for a new gas turbine disc alloy ${ }^{A}$. The paper emphasised the way a CALPHAD approach to predicting phase equilibria could accelerate the whole development programme by providing key input parameters for the design concepts. The paper mainly discussed issues associated with $\sigma$ and $\mu$ stability. In itself the input of the phase equilibrium input was decisive in the decision making process by which the chemistry of the final alloy was decided. As in the previous example, the CALPHAD route effectively provided a rapid experimentation route that allowed critical features of the alloy to be quantitatively designed on the computer and used in the alloy development process. The test matrix of experimental design alloys was then much reduced and, with features such as the $\gamma_{s}^{\prime}$ and amount of $\gamma^{\prime}$ under control, common thermo-mechanical treatment schedules were maintained for the experimental alloys.

As part of the development programme, the CALPHAD route was extended to predict anti-phase domain boundary (APB) energies. This information was used to maximise target mechanical properties so that design goals could be reached. The approach to predicting APB energies using a CALPHAD approach has been described in detail previously ${ }^{13}$ and can be summarised as follows.

In a perfectly ordered superlattice, such as the $\mathrm{Ll}_{2}$, the position of the various unlike and like atoms are prescribed by the ordering of the superlattice. When dislocations pass through this ordered structure a breakdown of local chemical order ensues with the subsequent creation of an APB. This boundary has a characteristic energy dependent on the change in the number of like and unlike bonds across the boundary. The number of such bonds across the APB is known from crystallographic considerations and, if the energy of the various bonds can be calculated, the APB energy can also be calculated.

If it is considered that the APB energy is predominantly controlled by the first nearest neighbours, i.e. second and higher order nearest neighbours are rclatively small in comparison, the APB energy is expressed only in terms of first nearest neighbour interactions, $W_{A A}, W_{B B}$ and $W_{A B}$. This leads to the following expressions $^{14}$,

$$
\mathrm{W}_{1}=\mathrm{W}_{\mathrm{AB}}-\frac{1}{2}\left(\mathrm{~W}_{\mathrm{AA}}-\mathrm{W}_{\mathrm{BB}}\right)
$$

where $W_{1}$ is the first nearer neighbour interaction energy. The APB energy is then given by

$$
A P B[h k l]=W_{1} a^{-2}\left[\frac{h}{\sqrt{\left(h^{2}+k^{2}+1^{2}\right)}}\right] .
$$

Eq.2 implies that APB[001] is equal to zero. However, experimental results suggest that the APB energy for the $\{001\}$ planes in $\mathrm{Ni}_{3} \mathrm{Al}$ is of the same order of magnitude as the $\{111\}$. It is therefore necessary to take into account energies up to at least the third nearest neighbour $\left(\mathrm{W}_{3}\right)$. The relevant equations for APB energies then take the form ${ }^{15,16}$

$$
\mathrm{APB}[111]=\mathrm{a}^{-2}\left(\frac{1}{3}\right)^{-\frac{1}{2}}\left[\mathrm{~W}_{1}-3 \mathrm{~W}_{2}+4 \mathrm{~W}_{3}-\ldots\right]
$$

and

$$
\mathrm{APB}[001]=\mathrm{a}^{-2}\left[-\mathrm{W}_{2}+4 \mathrm{~W}_{3}-\ldots .\right]
$$

To utilise these equations it is necessary to link the values of $W_{1}$, $\mathrm{W}_{2}$ and $\mathrm{W}_{3}$ with the Ni-database, which can be done using the Bragg-Williams-Gorsky ordering model ${ }^{13}$. In this case energy of formation of the $\gamma$ phase and the subsequent ordering energy to $\gamma^{\prime}$ are used as the critical input.

The model was tested on binary $L 1_{2}$ compounds before extending it to multi-component alloys. The end result was that a series of calculations for multi-component Ni-based superalloys were 
made and validated against experimental measurements. Figure 10 shows the comparison for this validation process and the agreement is very good.

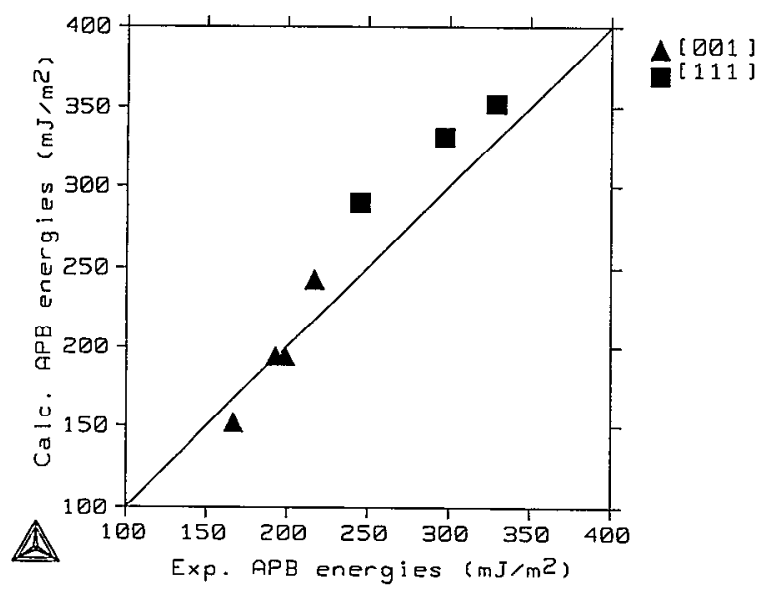

Figure 10: Comparison of calculated and experimentally measured $^{17}$ [111] and [001] APB energies for some superalloys

The advantage of using a calculation route is great. Firstly, the experimental measurement of APB energies is a taxing process, especially if the fault size is small. It requires great skill and expertise and, very importantly, the accuracy of measurement may be as much reliant on resolution of the electron microscope. Additionally, advances have been made in the correction methods applied to the raw measured data ${ }^{18}$. As a consequence the measured value of the APB energy has tended to increase with time (see for example Fig.3 in ref.13). The use of older measured values in theoretical equations may therefore incur inherent inaccuracy and it is useful to have a method of deriving values that is both internally self-consistent and can be verificd by independent recent experiments. The procedure for calculating the requisite energies is very simple and was routinely performed during the development of the new disc alloy.

Onc of the design criteria of the alloy was to meet a specified low cycle fatigue life while meeting all of the other mechanical property requirements in an acceptably stable alloy. To this end Mo levels were increased to strengthen the $\gamma$ matrix and $\mathrm{Ta}$ and $\mathrm{Ti}$ used to strengthen the $\gamma^{\prime}$. However, the alloying additions had to be balanced to ensure that (i) the amounts and solvus temperatures of the TCP phases $\sigma$ and $\mu$ were kept under control, (ii) the target $0.2 \%$ proof stress was achieved and (iii) the APB energy was kept sufficiently low for the deformation mechanism in the alloy to be cutting not climb. The latter provided planar slip rather than wavy slip and ensured that the low cycle fatigue life at high temperatures matched the design target.

The use of APB energy calculations to help control mechanical property requirements provided a clear enhancement to the value of a CALPHAD augmented alloy development approach. The design programme was progressed rapidly without the commitment of large amounts of time and resource in a 'traditional' experimental route. Further details of the alloy development programme will be given in another presentation at the current meeting ${ }^{19}$.

\section{TCP formation in Re-containing Single Crystal alloys.}

Recent alloy development of HP blades has almost exclusively relied on the addition of Re. Typically levels of between $2-6 w t \%$ are now added to single crystal alloys. Because $R e$ is such a heavy element, this relates to a very small addition in atomic terms, but the effect on properties such as creep and strength is very pronounced. $\operatorname{Re}$ also has a very profound effect on the solvus temperature for TCP formation, raising it substantially ${ }^{20,21}$. The reason for this is not readily understood in terms of a PHACOMP approach ${ }^{21}$, and it is therefore interesting to look at how CALPHAD methods can deal with Re.

In thermodynamic terms, $\mathrm{Re}$ is quite different to other elements that have a pronounced effect on TCP formation (e.g. $\mathrm{Cr}$ and Mo). It bears similarity to $\mathrm{Cr}$ in that a simple phase diagram between $\mathrm{Ni}$ and $\mathrm{Re}$ is formed with significant solubility of $\mathrm{Re}$ in Ni. However, in thermodynamic terms, $\operatorname{Re}$ forms very stable $\sigma$ phases with elements such as $\mathrm{Mo}, \mathrm{Cr}$ and $\mathrm{W}$. Further, these $\sigma$ phases contain high levels of $\operatorname{Re}(50-70$ at $\% R e)$. In contrast a "traditional" $\sigma$ phase containing $\mathrm{Ni}, \mathrm{Co}, \mathrm{Cr}, \mathrm{Mo}$ and $\mathrm{W}$ does not exhibit very negative heats of formation. In fact it is not always stable in the binary systems, only appearing in ternary and higher alloys. The corollary of both of these affects this is that Re strongly stabilises $\sigma$ in Ni-alloys, substantially more so than elements such $\mathrm{Cr}$, Mo and $\mathrm{W}$ and the partition coefficient, $\mathrm{x}_{\mathrm{Re}}^{\sigma} / \mathrm{x}_{\mathrm{Re}}^{\gamma}$ is very high.

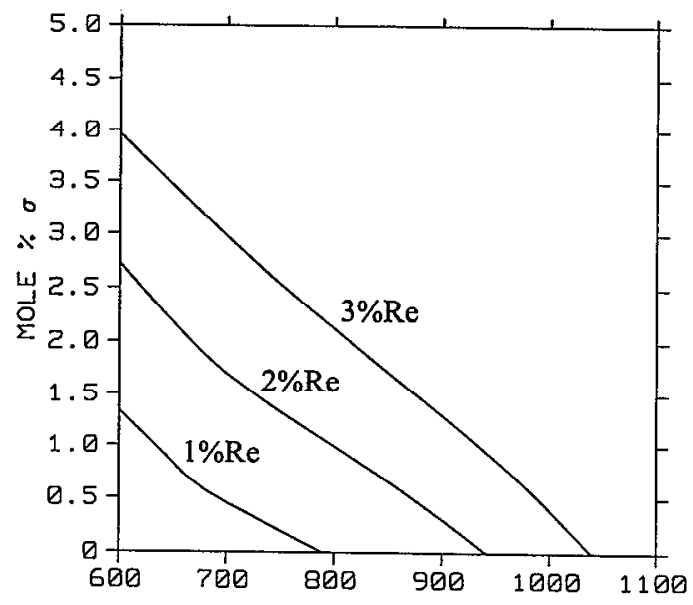

Figure 11: Predicted effect of Re on $\sigma$ formation in CMSX-422

Re has now been added to the Ni-database whereby the phase behaviour of commercial single crystal alloys can be calculated. The profound effect that $\operatorname{Re}$ has on $\sigma$ stability can be demonstrated by using a CMSX-4 alloy. CMSX-4 typically has the composition in wt\% Ni-6.3Cr-9Co-0.6Mo-6W-6.5Ta-3Re1Ti-0.1Hf. Figure 11 shows the effect on sigma formation when the $\operatorname{Re}$ concentration is changed from 3 to 1 wt $\%$ (at $0 \% \operatorname{Re}$ no sigma is predicted). It is clear that the effect of $R e$ is extremely strong, especially when considering that such a dramatic change in sigma stability is produced by an addition of only 1 at $\%$ Re. However, although clearly enhancing the formation of TCP 
phases the amount in the alloy is restricted by the total level of $R e$ because $\sigma$ is so rich in $\mathrm{Re}$. This has the corollary that $\mathrm{Re}$ containing single crystal alloys, such as CMSX-4, may be relatively tolerant to TCP formation even though their temperatures of formation can be very high.

In the present meeting Rae et $\mathrm{al}^{7}$ report work from an experimental programme looking at a Re-containing single crystal superalloy, RR2071. In this alloy 4 different TCP phases can form depending on the heat treatment. The composition of RR2071 is (in wt\%) Ni-9.5 Co-6.6Cr-4.5Mo-2.8Re-5.6Al-1.3Ti$7.3 \mathrm{Ta}-0.3 \mathrm{Nb}-0.1 \mathrm{Hf}$. The alloy was annealed at various temperatures for times of between 20 and $2600 \mathrm{hrs}$. The results ${ }^{7}$ are summarised below.

i) At $1000^{\circ} \mathrm{C}$ the alloy was observed to form only $\mathrm{P}$.

ii) At $950^{\circ} \mathrm{C}$ some $\mu$ is observed as well as $P$.

iii) At $900^{\circ} \mathrm{C} \sigma$ forms in the early stages before transforming to $\mu$.

iv) At $800^{\circ} \mathrm{C}$ the alloy is predominantly $\mu$ with some $\sigma$.

$\mathrm{R}$ was occasionally observed at the lower temperatures. It was noted that at $900^{\circ} \mathrm{C}$ and below $\sigma$ was the first phase to form, before transforming to the predominant $\mu$ phase. This feature was attributed to the more rapid transformation kinetics of $\sigma$, potentially arising from a favoured low energy $(1 \overrightarrow{1} 1)_{\gamma}$ interface.

Rae et al. ${ }^{7}$ analysed their experimental results using a previous version of the Ni-database. Although providing valuable information on stability of single crystal alloys, the predictions from this version were incorrect in terms of which phases would form. For example, only $\mathrm{P}$ was predicted to be stable. However, it was clear that the stability of all the TCP phases was very close and small changes in Gibbs energy would then shift the balance of stability meaning that one phase would then predominate over the other.

The database used in the present paper has since been extensively re-developed and includes new models for $\sigma$ and $\mu^{23}$. One of the effects of the new development work is that predictions for the equilibrium phases are now much closer to that observed. Figure 12 shows a calculated phase \% vs. Temperature plot for the RR2071 alloy using the new database. All features now appear

RR2071

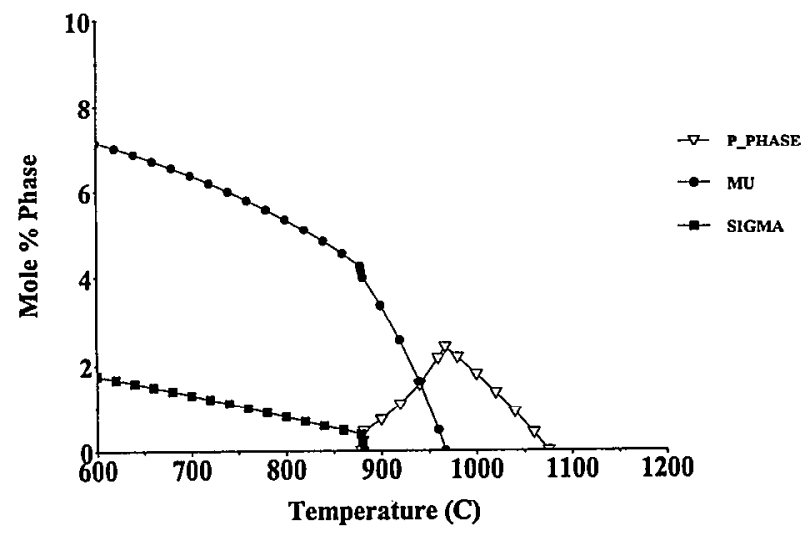

Figure 12: Calculated phase \% vs. Temperature plot for the experimental single crystal alloy $R R 2071$ accurately predicted, with the exception of the occasional observation of $R$.

At $1000^{\circ} \mathrm{C}$ the plot correctly shows the formation of $\mathrm{P}$ phase. At $950^{\circ} \mathrm{C}$ some small amount of $\mu$ is predicted in addition to P. At $900^{\circ} \mathrm{C} \mu$ has become the predominant phase, with only trace amounts of $\mathrm{P}$. Just below $900^{\circ} \mathrm{C}, \mathrm{P}$ disappears and $\sigma$ forms. The $\sigma$ phase then remains as a minor phase as the temperature is lowered. The absence of the $\sigma$ phase at $900^{\circ} \mathrm{C}$ is in accord with the observation by Rae et $a .^{7}$ that it is probably metastable at this temperature.

It is interesting to now look at two other single crystal alloys where quantitative experimental assessment of the phases has been performed. Following the example of Rae et al. ${ }^{7}, \mathrm{CMSX} 4$ and a Re-containing experimental "Alloy 800", studied by Proctor $^{24}$ and Darolia et al. ${ }^{21}$ respectively, have been used here.

Proctor $^{24}$ studied samples annealed at 1050 and $1150^{\circ} \mathrm{C}$ and found that, at these temperatures, CMSX4 is a $\mu$ stable alloy, with small amounts of $\mathrm{R}$ present at $1150^{\circ} \mathrm{C}$. At temperatures between 870 and $1150^{\circ} \mathrm{C}$, Darolia et al..$^{21}$ found that Alloy 800 contains predominantly $\mathrm{P}$ and $\sigma$, with some $\mu$ also present. Figure $13 \&$ Figure 14 show calculated phase \% vs. Temperature plots for both alloys.

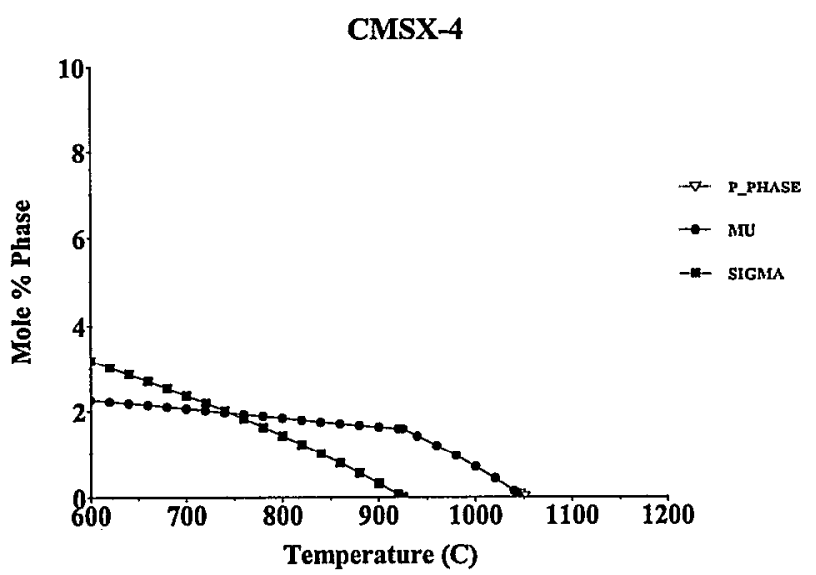

Figure 13 Calculated phase \% vs. Temperature plot for a CMSX-4 single crystal alloy

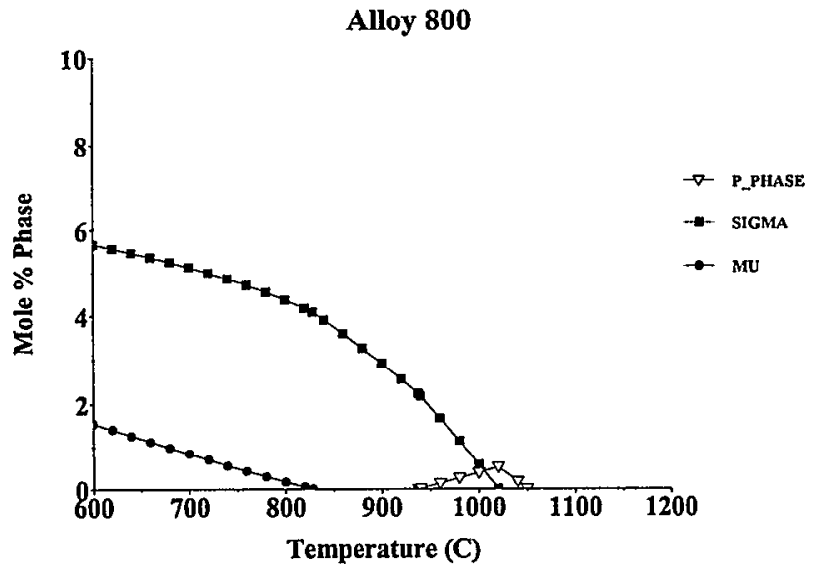

Figure 14: Calculated phase \% vs. Temperature plot for the experimental single crystal alloy $A 800$ 
CMSX -4 is correctly calculated to be $\mu$ dominant at higher temperatures with a small amount of $P$ forming just below the TCP solvus temperature. The calculations also predict that at lower temperatures $\sigma$ would form. Alloy 800 is predicted to be predominantly $P$ and $\sigma$ stable at the temperatures reported by Darolia et al. ${ }^{21}$, with $\mu$ forming at lower temperatures.

It is clear that the new database provides very good predictions for the TCP phases formed in single crystal alloys. The alloys used for comparison purposes exhibit distinctly different behaviour and the calculations represent almost exactly the phases that are observed. The comparison between experiment and calculation does however suggest that the calculated TCP solvus temperatures may be too low. For example,

(i) in CMSX-4 $\mu$ and $\mathrm{R}$ are observed at $1150^{\circ} \mathrm{C}$ while the highest TCP solvus temperature is calculated as $1050^{\circ} \mathrm{C}$,

(ii) in RR2071 P is observed at $1100^{\circ} \mathrm{C}$ while the calculated solvus temperature is $1075^{\circ} \mathrm{C}$ and

(iii) the maximum rate of TCP formation for alloy 800 is $1090^{\circ} \mathrm{C}$ while the calculated $\mathrm{P}$ solvus is $1050^{\circ} \mathrm{C}$.

It is, as yet, uncertain if this is due to a fault with the calculations or whether segregation remaining from casting is causing an enhanced susceptibility to TCP formation. Further work will be undertaken to resolve this question in the future.

\section{Summary and Conclusions}

The present paper has reported on recent developments to a database that can be utilised for CALPHAD-type thermodynamic calculations for Ni-based superalloys. These calculations allow features of both stablc and metastable phase equilibria to be calculated for a wide range of Ni-based superalloy types. Examples of its application to NiFe-based superalloys, disc alloys and single crystal alloys are given. It can also be used in the calculation of non-equilibrium transformations as demonstrated for a case of solidification modelling. Emphasis has been placed both on the validation of the database against experiment and the practical use of the calculations. As part of the present paper, the extension to predicting fundamental physical properties and mechanical behaviour is discussed and an example of its practical use in such circumstances presented. It is clear that the CALPHAD methodology has a role to play in many aspects of Ni-based superalloys use and development.

\section{References}

1. N. Saunders, Superalloys 1996 eds. R. D. Kissinger, D. J. Deye, D. L. Anton, A. D. Cetel, M. V. Nathal, T. M. Pollock, and D. A. Woodford (Warrendale, PA: TMS, 1996), 101

2. B. Sundman, "Thermo-Calc, a General Tool for Phase Diagram Calculations and Manipulations", User Aspects of Phase Diagrams, ed. F. H. Hayes, (London: Inst.Metals, 1991) 130

3. N. Saunders and A. P. Miodownik, CALPHAD - Calculation of Phase Diagrams, Pergamon Materials Series vol.1, ed. R. W. Cahn, (Oxford: Elsevier Science, 1998)

4. C. J. Small and N. Saunders, "Development of a New Gas Turbine Disc Alloy", MRS Bulletin, 24, (1999), 22

5. N. Saunders, "Modelling of Nickel-Base Superalloys", Advanced Materials \& Processes, 156, (1999), 29
6. M. G. Fahrmann and G. D. Smith, "Capitalizing on Computational Tools in Alloy and Process Development" to be published in Proc.Symp.Advanced Technologies for Superalloy Affordability (Warrendale, PA: TMS, 2000)

7. C. M. F. Rae, M. Karunatatne, C. J. Small, R. W. Broomfield, C. N. Jones and R. C. Reed, "Topologically Close Packed Phases in an Experimnetal Re-containing Single Crystal Superalloy", presented at $9^{\text {th }}$ International Symposium on Superalloys, Seven Springs, PA, 2000

8. B. A. Boutwell, R. G. Thompson, N. Saunders, S. K. Mannan, and J. J. deBarbadillo, "Phase Formation Modeling of an Alloy 706 Casting Using Computational Thermodynamics", Superalloys 718, 625, 706 and Various Derivatives, ed. E. A. Loria, (Warrendale, PA: TMS, 1996), 99

9. A. O Basile and J. F. Radavich "A Current TTT Diagram for Wrought Alloy 718", Superalloy 718, 625 \& Various Derivatives, ed. E. A Loria, (Warrendale, PA:TMS, 1991), 325

10. B. A. Lindsley, X. Pierron, G. E. Maurer, J. Radavich, " $\alpha-C r$ Formation in Alloy 718 During Long Term Exposure: The Effects of Chemistry and Deformation", Long Term Stability of High Temperature Materials, eds.G. E Fuchs, K. A. Dannemann and T. C. Deragon, (Warrendale, PA: TMS, 1999.) 123

11. W. J. Boettinger, U. R. Kattner, S. R. Coriell, Y. A. Chang and B. A. Mueller, "Development of Multi-Component Solidification Micromodels Using a Thermodynamic Phase Diagram Database" Modeling of Casting, Welding and Advanced Solidification Processes, VII, eds. M. Cross and J. Campbell, J. (Warrendale, PA: TMS 1995) 649

12. N. Saunders, "Applicability of the Equilibrium and 'Scheil Model' to Solidification in MultiComponent Alloys", Solidification Processing 1997" eds. J. Beech and H. Jones (Univ.Sheffield: 1997) 362

13. A. P. Miodownik and N. Saunders "The calculation of APB Energies in $\mathrm{Ll}_{2}$ Compounds Using a Thermodynamic Database", Applications of Thermodynamics in the Synthesis and Processing of Materials, eds. P. Nash and B. Sundman, (Warrendale, PA: TMS, 1995), 91

14. P. A. Flinn, "Theory of Deformation in Superlattices", Trans.Met.Soc.AIME, 218, (1960), 145

15. G. Inden, S. Bruns and H. Ackermann, "The Energy of Mechanically Produced Antiphase Boundaries (APB) in $\mathrm{Ll}_{2}$ and L1 $1_{0}$ Ordered FCC Alloys", Phil.Mag.A, 53, (1986) 87

16. A. G. Khachaturyan and J. W. Morris Jr., "The Interfacial Tension of Antiphase Domain Boundaries", Phil.Mag.A., 56, (1987), 517

17. W. M. Stobbs, "Measurement of APB Energy in a Series of Ni-based Alloys", Univ.Cambridge report to Rolls-Royce plc., Derby, U.K. 1993

18. N. Baluc, R. Schaublin and K. J. Hemper, "Methods for Determining Precise Values of Antiphase Boundary Energies in $\mathrm{Ni}_{3} \mathrm{Al}^{\prime}$, Phil.Mag.Lett., 64, (1991), 327

19. M.Hardy, C.J.Small, S.A.Franklin and D.J.Bryant, "The development of a new Ni-alloy for disc applications up to $725^{\circ} \mathrm{C}^{\prime \prime}$, presented at $9^{\text {th }}$ International Symposium on Superalloys, Seven Springs, PA, 2000

20. G. L. Erickson, K. Harris and R. E. Schwer, "The Development of CMSX-5 a $3^{\text {rd }}$ Generation High Strength Single Crystal Alloy" presented at the TMS Annual Meeting, New York, 1985

21. R. Darolia, D. F. Lahrman R. D. Field, "Formation of Topologically Closed Packed Phases in Nickel Base Single Crystal Superalloys", Superalloys 1988, eds. S. Reichman, D.N. 
Duhl, G. Maurer, S. Antolovich and C. Lund (Warrendale, PA: TMS, 1988) 255

22. N. Saunders, "Calculated Phase Equilibria and its Use in Predicting Long Thermal Stability in Complex Alloys", Long Term Thermal Stability of High Temperature Materials, eds. G. E Fuchs, K. A. Dannemann and T. C. Deragon. (Warrendalc, PA: TMS, 1999), 81

23. N. Saunders, Ni-DATA ver.4, Thermotech Ltd., The Surrey Research Park, Guildford, Surrey, UK

24. C. S. Proctor, "Formation and Effects of Intermetallics in the Rhenieum-containing Nickel-base Superalloy CMSX-4", (Ph. D. Thesis, University of Cambridge, 1993) 